\title{
ASSÉDIO MORAL NO TRABALHO SOB A PERSPECTIVA DA PREVIDÊNCIA SOCIAL E A POSSIBILIDADE DE SUA EQUIPARAÇÃO A ACIDENTE DE TRABALHO
}

\section{PSYCHOLOGICAL HARASSMENT AT WORK UNDER THE PERSPECTIVE OF SOCIAL SECURITY AND THE SUITABILITY OF ITS EQUALIZATION TO WORK ACCIDENT}

\author{
Gabrielle Ota Longo ${ }^{1}$ \\ Victor Hugo de Almeida ${ }^{2}$
}

\section{RESUMO}

Destinou-se este trabalho a investigar o tratamento conferido ao assédio moral pela Previdência Social, a partir da análise de dados extraídos de seus Anuários Estatísticos, e situá-lo enquanto fator contemporâneo de precarização do trabalho, buscando-se ampliar a visão de acidente de trabalho. Consistindo o assédio moral em um gravíssimo problema a desafiar uma solução urgente para a efetiva proteção à saúde mental do trabalhador, dentre as propostas fundamentadas nas repercussões sociojurídicas do fenômeno, evidenciou-se, através de análise crítica do Projeto de Lei $\mathrm{n}^{\circ} 7.202 / 2010$, a adequabilidade da equiparação do assédio moral no contexto laboral ao acidente de trabalho (FAPESP).

Palavras-chave: Assédio Moral; Acidente de Trabalho; Direitos Sociais; Saúde Mental do Trabalhador; Previdência Social.

\begin{abstract}
This research was intended to investigate the treatment given to psychological harassment by Social Security, from the analysis of data extracted from its Statistical Yearbooks, and to situate it as contemporary factor of precarious work, seeking to expand the view of occupational accident. As psychological harassment is a serious problem to challenge an urgent solution to the effective protection of worker's mental health, among the proposals based on the legal and social impact of the phenomenon, it was evidenced, through critical analysis of Bill n. 7.202/2010, the suitability of equalization of psychological harassment in employment context to accident work (FAPESP).
\end{abstract}

Keywords: Psychological Harassment; Accident Work; Social Rights; Worker's Mental Health; Social Security.

\footnotetext{
${ }^{1}$ Mestranda em Direito pela Faculdade de Direito de Ribeirão Preto da Universidade de São Paulo - USP, (Brasil). E-mail: gabrielleota@hotmail.com

2 Doutor em Direito pela Faculdade de Direito da Universidade de São Paulo - FDUSP, (Brasil). Professor Doutor da Universidade Estadual Paulista , UNESP, São Paulo, (Brasil).

E-mail: victorhugo.professor@gmail.com
} 


\section{INTRODUÇÃO}

Em manifesta afronta à salvaguarda da dignidade humana na esfera laboral e de um meio ambiente do trabalho equilibrado, que emergiu após longo processo de lutas sociais e reivindicações dos trabalhadores, tem se disseminado no meio ambiente laboral um fenômeno caracterizado pela potencialidade de submeter os trabalhadores a uma violência psicológica e agredir sua integridade psicofísica, por meio de reiterado tratamento perverso e humilhante.

Nessa conjuntura, este estudo buscou verificar o tratamento conferido ao assédio moral pela Previdência Social, a partir de dados extraídos de Anuários Estatísticos previdenciários, além de investigar seus impactos na saúde mental do trabalhador, situando-o, na perspectiva labor-ambiental (aspectos físicos e biopsicossociais do meio ambiente do trabalho), enquanto fator contemporâneo da precarização do trabalho, com vistas à melhoria da qualidade de vida dos trabalhadores.

Para tanto, adotou-se, como método de procedimento, o levantamento de dados por meio da técnica de pesquisa bibliográfica em materiais publicados (por exemplo, artigos, legislação, doutrinas, anuários estatísticos do Ministério da Previdência Social, entre outros) e, como métodos de abordagem, o dedutivo e o comparativo.

A princípio, examinou-se noções acerca do meio ambiente do trabalho dispostas na literatura jurídica, de modo a compreender a sua abrangência, os aspectos físicos e biopsicossociais que o constituem, a sua inter-relação com outros contextos ambientais, bem como a necessária proteção da saúde mental dos obreiros.

No título seguinte, delineou-se o instituto do assédio moral na perspectiva trabalhista, perpassando pelo conceito doutrinário, suas espécies, seus elementos caracterizadores e pelo tratamento a ele dispensado pelo Direito Pátrio. Ainda, foram elencadas consequências do assédio moral à saúde psíquica do trabalhador, como os transtornos mentais e comportamentais relacionados ao trabalho.

Posteriormente, investigou-se o tratamento conferido ao assédio moral pela Previdência Social. Para tanto, procedeu-se com o levantamento e a análise de dados estatísticos extraídos dos Anuários Estatísticos de 2006 a 2014, disponibilizados no endereço eletrônico do Ministério da Previdência Social. Com embasamento na Classificação 
Estatística Internacional de Doenças e Problemas Relacionados à Saúde (CID-10), foram selecionados os acidentes de trabalho relacionados à saúde mental do trabalhador, divulgados através dos Anuários Estatísticos do período de 2006 a 2014, bem como os auxílios-doença acidentários concedidos entre janeiro de 2006 a junho de 2016. Por conseguinte, analisou-se a adequabilidade da equiparação do assédio moral ao acidente de trabalho, conforme propõe o Projeto de Lei $\mathrm{n}^{\circ} 7.202 / 2010$.

Por fim, com vistas ao enfrentamento do problema, abordaram-se os principais impactos labor-ambientais do assédio moral, evidenciando-se a eficácia de ações preventivas capazes de evitá-lo, cuja medida pode contribuir para reduzir as estatísticas previdenciárias relacionadas à saúde mental do trabalhador.

\section{A FUNDAMENTALIDADE DO MEIO AMBIENTE DO TRABALHO: UMA VISÃO LABOR-AMBIENTAL BIOPSICOFÍSICA}

Resultado da chamada multiplicação de direitos (BOBBIO, 1992), emergem, após a Segunda Guerra Mundial, duas tendências marcantes que, gradativamente, conquistaram espaço no atual mundo globalizado: a preocupação com o meio ambiente e a busca por uma melhor qualidade de vida.

Guilherme Guimarães Feliciano (2006) destaca que, não obstante a definição de meio ambiente seja unitária, ele tem sido classificado pela doutrina brasileira em quatro dimensões particulares: natural, artificial, cultural e meio ambiente do trabalho. Cabe ao Direito do Trabalho primar pela regulamentação e promoção de um meio ambiente laboral sadio e equilibrado, bem como contribuir para a sua preservação.

O meio ambiente do trabalho é o local onde o trabalhador passa grande parte de seu cotidiano, razão pela qual o seu equilíbrio e higidez dependem de um conjunto de fatores físicos, químicos, biológicos, climáticos e comportamentais que interagem entre si e com o trabalhador (ALMEIDA; COSTA; GONÇALVES, 2013). Trata-se de manifestação particular do meio ambiente geral, uma unidade autônoma com leis próprias, porém dependente de uma estrutura sistêmica, à luz da Gestalt (FELICIANO, 2006).

A compreensão de meio ambiente laboral não mais se restringe, como outrora, aos aspectos físicos constitutivos das "edificações do estabelecimento" de trabalho - a exemplo de objetos, ferramentas, máquinas, equipamentos de proteção individual, estrutura da construção, disposição espacial e elementos químicos - (NASCIMENTO, 2013, p. 868), da 
mesma forma em que os danos à saúde do trabalhador e ao meio ambiente não estão limitados àquelas (MELO, 2001). Passou-se a considerar que o meio ambiente laboral compreende tudo aquilo que circunda o trabalhador, não se circunscrevendo apenas ao estabelecimento no qual ocorre o exercício do trabalho, mas abrangendo os fatores biopsicossociais e tudo o que possa afetar sua saúde psicofísica, sua segurança e seu bem-estar.

Para além do local onde o trabalhador desenvolve suas atividades, o meio ambiente do trabalho é um "locus dinâmico" (ROCHA, 2002, p. 127), constituído por todos os elementos materiais e imateriais que, direta ou indiretamente, relacionam-se com a execução do trabalho (BRANDÃO, 2010, p. 28).

Neste sentido, além de aspectos físicos (como ar, água, terra, bens tangíveis pelo ser humano, entre outros), o meio ambiente abarca aspectos sociais (a exemplo de valores culturais, hábitos, costumes, crenças, etc.), bem como aspectos psíquicos humanos (como sentimento, expectativas, segurança, angústia, estabilidade, dentre outros). Isso se deve ao fato de que os meios físico, social e psíquico conferem condições interdependentes, necessárias e suficientes para que o organismo vivo (planta ou animal), também detentor de aspectos biológicos, desenvolva-se em sua plenitude (ALMEIDA; COSTA; GONÇALVES, 2013).

Os fatores psicossociais no trabalho são as interações entre o trabalho, seu meio ambiente, a satisfação no trabalho e as condições de organização, como também as capacidades, necessidades, cultura e situação do trabalhador fora do ambiente laboral. Há fatores potencialmente negativos, a exemplo da má-utilização das habilidades, da sobrecarga de trabalho, da desigualdade no trabalho, da falta de segurança no meio ambiente laboral e dos problemas nas relações de trabalho. Todos esses aspectos podem interferir de modo decisivo no bem-estar físico e mental dos trabalhadores, no seu rendimento e na satisfação pelo trabalho, podendo, inclusive, culminar em diminuição da saúde. Tais fatores de risco atuam de forma integrada para potencializar os efeitos nocivos (PENIDO; PERONE, 2015).

\subsection{A inter-relação entre meio ambiente do trabalho e outros contextos ambientais}

De forma semelhante às relações humanas, que se irradiam dando origem a inúmeros círculos diferentes, os ambientes nos quais o ser humano está inserido estão sujeitos a interações recíprocas e interinfluências (DUARTE; ALMEIDA, 2015). Por isso, não há como compreender o meio ambiente de trabalho dissociado das demais manifestações ambientais, ao mesmo passo que não é possível isolar o indivíduo-trabalhador do indivíduo-social. O 
trabalhador não pode deixar toda a sua história pessoal no portão de entrada da empresa, da mesma forma como não se concebe que, ao final do expediente, ele retire do corpo físico e mental toda a carga de significado imposta pelo dia de trabalho (OLIVEIRA, 2002).

Constata-se uma inter-relação entre o meio ambiente do trabalho e outros contextos ambientais, na medida em que os danos ambientais não se restringem, obrigatoriamente, ao ambiente laboral, perseguindo, não raras vezes, o trabalhador após o expediente. Em geral, ocorre uma significativa ingerência do ambiente físico de trabalho e de suas características específicas na relação entre o ambiente laboral e a saúde dos obreiros, em razão da interdependência dos aspectos físicos do ambiente e dos aspectos psicológicos do trabalhador, que estão em constante interação e modificação.

O paradigma constitucional insculpido no art. 200, inciso VIII, da Constituição Federal (CF), esclarece que tanto a saúde como a qualidade de vida do trabalhador dependem de toda a estrutura sistêmica ambiental, de modo que "o trabalhador influi e é influenciado tanto pelos aspectos do contexto em que se encontra diretamente (meio ambiente do trabalho) como pelos aspectos de outras estruturas ambientais interdependentes" (ALMEIDA; COSTA; GONÇALVES, 2013, p. 135). Trata-se da necessária concepção sistêmica do meio ambiente laboral elucidada pelo princípio da interdependência ambiental.

\subsection{A proteção da saúde mental do trabalhador}

Após a Revolução Industrial e a regulamentação das relações de trabalho, verificouse uma alteração do modo de se compreender e tratar a relação entre saúde e trabalho. A concepção de saúde passou por inúmeras transformações, readaptando-se às necessidades temporais, aos anseios sociais e os princípios estabelecidos pela Constituição Federal.

Séculos atrás, ao se pensar em saúde, destacava-se apenas o seu aspecto físico. Atualmente, a saúde mental tem sido demasiadamente afetada, culminando em danos de grande intensidade na vida do trabalhador, de forma a merecer especial atenção dos legisladores, estudiosos e de todos aqueles que pretendem a real efetivação das normas protetivas da saúde dos obreiros.

A Constituição Federal consagra em seu art. $6^{\circ}$ a saúde como um direito social. Trata-se de um direito de todos e dever do Estado, consoante ao disposto no art. 196 constitucional, que deve ser garantido mediante políticas sociais e econômicas que visem à redução do risco de doença e de outros agravos, bem como ao acesso universal e igualitário às 
ações e serviços para a sua promoção, proteção e recuperação. No âmbito do trabalho, conforme Victor Hugo de Almeida e André Evangelista de Souza (2013, p. 154), “a saúde se mostra como um conteúdo mínimo e inarredável, criador de normas de ordem pública, que permite fixar os limites de atuação do capital (leia-se, poder de direção do empregador) frente à dignidade do trabalhador".

A Lei Orgânica da Saúde (Lei $\left.{ }^{\circ} 8.080 / 90\right)$, por sua vez, dispõe em seu art. $3^{\circ}$ que a saúde tem como determinantes e condicionantes, entre outros, o meio ambiente e o trabalho. Já a Convenção $\mathrm{n}^{\circ} 155$ da Organização Internacional do Trabalho (OIT) estabelece, em seu art. $3^{\circ}$, alínea $e$, que, em relação ao trabalho, a saúde abrange não apenas a ausência de afecções ou de doenças, mas também os elementos físicos e mentais que a afetam e estão diretamente relacionados com a segurança e a higiene do trabalho (ORGANIZAÇÃO INTERNACIONAL DO TRABALHO, 1983).

Embora as normas protetivas da saúde do trabalhador estejam dispersas no ordenamento jurídico brasileiro em diversos regramentos (Constituição Federal, decretos, legislação infraconstitucional, convenções e normas regulamentadoras), o bem-estar físico e mental do trabalhador compõe o direito fundamental à saúde, sendo, por isso, um direito essencial à vida humana, cabendo a todos os atores sociais efetivá-lo. A garantia da saúde e segurança no meio ambiente do trabalho abrange a proteção contra os riscos e agentes nocivos que possam lá se encontrar (psicossociais, físicos, químicos, biológicos ou ergonômicos), devendo alcançar, também, o ingresso e a permanência dos trabalhadores em um ambiente laboral adaptado às suas características psicológicas e fisiológicas (PENIDO, 2015).

\section{ASSÉDIO MORAL COMO FATOR CONTEMPORÂNEO DE PRECARIZAÇÃO DO TRABALHO}

Por assédio moral entende-se qualquer comportamento abusivo, manifestado por meio de palavras faladas e escritas, gestos e atos, de natureza reiterada, sistemática e intencional, contra a dignidade e a integridade psicofísica do trabalhador, ameaçando seu emprego e desequilibrando o meio ambiente do trabalho. Trata-se de uma violência subreptícia, não assinalável, mas muito destrutiva (HIRIGOYEN, 2015).

$\mathrm{O}$ assédio moral classifica-se em vertical, horizontal e misto. O assédio moral vertical é típico de relações caracterizadas pela subordinação e por diferentes posições hierárquicas, subdividindo-se em descendente e ascendente. 
Denomina-se descendente o assédio praticado por indivíduo que ocupa posição hierárquica superior em face de outro que a ele é subordinado; busca eliminar a vítima ou valorizar o próprio poder (assédio perverso), para pressionar o assediado a pedir demissão e, assim, evitar os procedimentos legais da dispensa (assédio estratégico), ou pode consistir em um instrumento de gestão da equipe (assédio institucional). $\mathrm{O}$ assédio moral ascendente tem como agressor ou agressores um ou vários subordinados e, como vítima, um superior hierárquico; esta hipótese ocorre com certa frequência no serviço público e por ocasião de fusões de empresas ou da compra de um grupo empresarial por outro (NASCIMENTO, 2011), podendo ser igualmente destrutivo.

Designa-se horizontal o assédio praticado entre trabalhadores que se inserem no mesmo nível hierárquico, sem qualquer relação de subordinação. Essa espécie de assédio ocorre com frequência quando dois empregados disputam um mesmo cargo ou promoção (HIRIGOYEN, 2015).

A caracterização do assédio moral misto impõe, no mínimo, três sujeitos: o assediador vertical, o assediador horizontal e a vítima, que é ofendida pelos dois assediadores. Neste contexto, ressalta-se a necessidade de identificar o agressor principal, o responsável pelo início de todo o processo (HIRIGOYEN, 2015).

Destaca-se, por fim, o assédio moral organizacional, que envolve um conjunto sistemático de práticas reiteradas, derivadas de métodos de gestão empresarial, com o intuito de atingir metas relacionadas ao aumento de produtividade e à diminuição do custo do trabalho, valendo-se, para tanto, de pressões, humilhações e constrangimentos aos trabalhadores da empresa (ALVARENGA, 2012).

\subsection{Elementos caracterizadores do assédio moral}

O assédio moral é caracterizado pela conduta abusiva, de natureza reiterada, sistemática e intencional, contrária à dignidade e à integridade psicofísica do trabalhador, consistindo, em regra, em ameaça ao emprego e culminando no desequilíbrio do meio ambiente do trabalho.

A conduta abusiva pode ser manifestada por palavras, gestos, atos e/ou escritos, implicando em recusa de comunicação direta com a vítima, desqualificação, descrédito, constrangimento, marginalização do sujeito mediante tratamento hostil e indiferente, indução 
do assediado a erro, críticas contínuas a seus atos, atribuição de tarefas que inferiorizam e são humilhantes, ou difíceis demais de cumprir, entre outros.

A configuração do assédio moral depende da repetição da conduta, de forma meticulosa, contínua e proposital, por se tratar de ato que só adquire significado pela insistência. Assim, conforme Sônia Mascaro Nascimento (2015), fazem-se necessárias a frequência (no mínimo uma vez por semana), a duração (pelo menos seis meses) e, de acordo com Marie-France Hirigoyen (2005) o consequente efeito cumulativo dos microtraumatismos frequentes e repetidos (HIRIGOYEN, 2015).

A prática do terror psicológico, além de ofender o princípio da dignidade humana do trabalhador, viola seus direitos da personalidade e sua integridade física e psíquica. Alguns aspectos como o "animus desestabilizador" (BENGOECHEA, 2003, p. 204) e o perfil psicológico autoritário e narcisista do assediador contribuem para a configuração da violência.

Ainda, o propósito de eliminar o assediado do ambiente de trabalho acaba por comprometer o pleno e adequado desempenho de suas atividades laborativas, ameaçar o emprego da vítima e afetar o equilíbrio e a higidez do meio ambiente laboral, resultando em graves prejuízos à saúde mental do trabalhador. Trata-se de uma conduta contrária à própria Constituição Federal, às normas celetistas, em especial aos artigos 482 e 483 da Consolidação das Leis do Trabalho, configurando, inclusive, o descumprimento, por parte do empregador, de suas obrigações contratuais.

Em contrapartida, segundo Sônia Mascaro Nascimento (2015), não qualificam atos de assédio moral profissões ou atividades naturalmente estressantes, desavenças esporádicas entre colegas de trabalho e/ou chefias, práticas discriminatórias isoladamente realizadas, manifestações legítimas oriundas do poder diretivo do empregador, como transferências de trabalhadores, mudanças de funções, avaliações de desempenho, imposição de metas, cobranças e críticas ao trabalho, desde que se deem de forma objetiva e respeitosa.

\subsection{O assédio moral na perspectiva do Direito Pátrio}

No Brasil, a prática de assédio moral no meio ambiente de trabalho é definida e disciplinada, pormenorizadamente, somente em relação ao serviço público, mediante inúmeras leis municipais e estaduais, voltando-se muitas delas à perspectiva preventiva do assédio. Assim, não há lei específica, de abrangência nacional, que proteja os trabalhadores da iniciativa privada e os servidores públicos federais contra a prática do assédio moral. 
A despeito disso, entende-se que tal prática é vedada pela legislação trabalhista, por se enquadrar o assédio moral horizontal na hipótese de incontinência de conduta ou mau procedimento (art. 482, alínea b, CLT), constituindo justa causa para rescisão do contrato de trabalho pelo empregador, em relação ao empregado-assediador. $\mathrm{O}$ assédio moral vertical, por sua vez, é hipótese de rescisão indireta (art. 483, alíneas a, b, e, f, CLT), podendo conferir ao empregado o direito de pleitear a devida indenização.

A reprovação da prática do assédio moral pode ser verificada em alguns dispositivos legais, como no art. $4^{\circ}$ da Lei $n^{\circ} 11.948$, de 16 de junho de 2009, que veda a concessão ou renovação de quaisquer empréstimos ou financiamentos pelo BNDES a empresas da iniciativa privada cujos dirigentes sejam condenados por assédio moral, entre outros. Também, no contexto do trabalho nas centrais de teleatendimento ou telemarketing (Call Center), encontra-se vedada a utilização de métodos que causem assédio moral, medo ou constrangimento, conforme dispõe o item 5.13 do Anexo II da Norma Regulamentadora (NR) $\mathrm{n}^{\mathrm{o}} 17$ (Ergonomia), do Ministério do Trabalho e Emprego (MTE), aprovado pela Portaria da Secretaria de Inspeção do Trabalho ${ }^{\circ}$ 09, de 30 de março de 2007.

Neste contexto, destacam-se alguns projetos de lei, como o PL n ${ }^{\circ} 5.970 / 2001$, que propôs a alteração do artigo 483, alínea g, parágrafo $3^{\circ}$, e do artigo 484-A, ambos da CLT, para incluir o assédio moral (denominado "coação moral”) no rol de hipóteses que justificam a rescisão indireta do contrato individual de trabalho, mediante o pagamento das respectivas indenizações.

O legislador brasileiro também sugeriu criminalizar a conduta em menção, tipificando a prática do assédio moral por meio da inclusão do art. 146-A no Código Penal, pretendida pelo PL n ${ }^{\circ}$ 4.742/2001, que prevê a pena de detenção, de um a dois anos, para a prática delituosa. Embora o texto apresentado, se aprovado, representará um avanço, ele alcança somente o assédio moral vertical descendente. A este estão apensados outros projetos de lei que visam alterar dispositivos legais do Código Penal, para criminalizar a conduta em face do poder de lesividade do assédio moral. 


\subsection{Consequências do assédio moral à saúde psíquica do trabalhador: os transtornos mentais e comportamentais como causas de afastamento do trabalho}

Além de armas como o amianto, o agrotóxico, a prensa, o cabo de aço esgarçado, o cinto de segurança que não foi fornecido, a máquina sem manutenção, dentre tantas outras, a prática do assédio moral consiste em mais uma arma, com elevado potencial ofensivo, a ser combatida. No Brasil, os seus reflexos no meio ambiente do trabalho e na saúde mental do trabalhador são reconhecidos como causas de transtornos mentais, identificados, por sua vez, como doenças do trabalho. Ainda que não desencadeie um quadro clínico de distúrbio mental, continua representando uma fonte de desgaste e sofrimento psíquico (SELIGMANN-SILVA; FIGUEIREDO; FRANCO, 2015), cujos principais sintomas são insônia, cansaço, irritabilidade, dores de cabeça, palpitações, diarreias nervosas e outras alterações de natureza psicossomática.

A princípio, os sintomas do assédio moral se assemelham aos do estresse (autodefesa do organismo a uma hiperestimulação consistente na necessidade de enfrentar a situação), classificados pela medicina como perturbações funcionais (HIRIGOYEN, 2015). Porém, se o assédio se prolongar por mais tempo ou recrudescer, depressões de diferentes categorias podem ser suscitadas. Em geral, a vítima apresenta apatia, tristeza, complexo de culpa, obsessão, ansiedade, sintomas psicóticos e, inclusive, desinteresse pelos seus próprios valores.

Decorridos vários meses de assédio moral, o quadro clínico pode evoluir para um transtorno de estresse pós-traumático (TEPT) ou para modificações duradouras de personalidade e quadros de fobia e psicose (HIRIGOYEN, 2015). O TEPT caracteriza-se como uma resposta tardia e/ou protraída a um evento ou situação estressante de natureza ameaçadora ou catastrófica (MINISTÉRIO DA SAÚDE, 2001), e o assédio moral firma-se enquanto uma situação traumática inconteste. Além do afastamento do trabalho para tratamento, é comum que o desenvolvimento do TEPT torne necessário um projeto de reabilitação profissional, pois as sequelas podem impedir o retorno do empregado ao seu posto de trabalho anterior (MINISTÉRIO DA SAÚDE, 2001).

Distúrbio frequentemente acarretado pelo assédio moral, a síndrome de burnout (ou síndrome do esgotamento profissional) consiste em uma reação cumulativa crônica de contínuos estresses ocupacionais e se caracteriza pela exaustão emocional (sentimentos de desgaste emocional e esvaziamento afetivo), despersonalização (reação negativa, insensibilidade ou distanciamento das pessoas, especialmente dos colegas de trabalho) e pela 
autodepreciação (sentimento de diminuição de competência e de sucesso no trabalho) (MINISTÉRIO DA SAÚDE, 2001).

A dependência de bebidas alcoólicas ou drogas, relacionada ao trabalho também pode ser desencadeada ou agravada pelo assédio moral, podendo constituir uma prática escapista e defensiva adota pela vítima, com o objetivo de suportar o terror psicológico a que está submetido. Para se diagnosticar o uso patológico de bebidas alcoólicas, fazem-se necessárias três ou mais manifestações conjuntas durante o período máximo de um mês, reiteradamente por doze meses, e ficar demonstrada a relação das ocorrências com o trabalho.

Ao final, destaca-se o intenso risco de suicídio por parte das vítimas de assédio moral no ambiente de trabalho, que pode resultar de uma sucessão de episódios traumáticos. Tratase de um ato extremo, cometido ou tentado por trabalhadores imersos em profundo sofrimento, determinado pelo ambiente ocupacional. (BARUKI, 2015).

\section{ACIDENTES DE TRABALHO, SAÚDE PSÍQUICA DO TRABALHADOR E BENEFÍCIOS ACIDENTÁRIOS CONCEDIDOS PELA PREVIDÊNCIA SOCIAL}

A Lei $\mathrm{n}^{\mathrm{o}}$ 8.213, de 24 de julho de 1991, em seu art. 19, define o acidente de trabalho como aquele ocorrido a serviço da empresa, ou de empregador doméstico (acrescentado pela Lei Complementar $n^{\circ} 150$, de 2015), causando lesão corporal ou perturbação funcional que culmine em morte, perda ou redução da capacidade para o trabalho, transitória ou permanente.

No Brasil, desde a implantação da sistemática do Nexo Técnico Epidemiológico Previdenciário (NTEP), em abril de 2007, a Previdência Social considera como acidentes do trabalho, além dos denominados típicos, os acidentes de trajeto, as doenças profissionais e as doenças do trabalho, informados ou não por meio de Comunicação de Acidente de Trabalho (CAT).

Destacam-se as doenças do trabalho como aquelas adquiridas ou desencadeadas em razão de condições especiais em que o trabalho é realizado e com ele se relacione diretamente, fazendo-se necessário o reconhecimento técnico do nexo de causalidade entre a doença e o trabalho, por meio de perícia médica realizada pelo Instituto Nacional do Seguro Social (INSS), para restar configurada esta modalidade de acidente de trabalho. 


\subsection{Acidentes do trabalho segundo a Classificação Estatística Internacional de Doenças e Problemas Relacionados à Saúde - CID-10}

Considerando-se os 200 códigos da Classificação Estatística Internacional de Doenças e Problemas Relacionados à Saúde (CID-10), dentre os acidentes do trabalho mais incidentes no Brasil discriminados no Anuário Estatístico da Previdência Social foram encontrados oito relacionados à saúde mental dos trabalhadores. Pode-se comparar a quantidade de ocorrência dos referidos acidentes de trabalho, no período compreendido entre os anos de 2006 a 2014, por meio da Tabela 1, a seguir apresentada.

Tabela 1: Dados dos oito acidentes de trabalho que impactam a saúde mental do trabalhador, segundo o Ministério da Previdência Social.

\begin{tabular}{|c|c|c|c|c|c|c|c|c|c|}
\hline & 2006 & 2007 & 2008 & 2009 & 2010 & 2011 & 2012 & 2013 & 2014 \\
\hline $\begin{array}{l}\text { F43: Reações ao "stress" grave e } \\
\text { transtornos de adaptação }\end{array}$ & 3.037 & 5.278 & 7.119 & 6.412 & 6.002 & 6.588 & 7.892 & 9.121 & 9.078 \\
\hline F32: Episódios depressivos & 389 & 3.601 & 5.205 & 4.908 & 4.116 & 4.006 & 3.628 & 3.935 & 3.634 \\
\hline F41: Outros transtornos ansiosos & 558 & 864 & 1.923 & 2.482 & 2.366 & 2.563 & 2.741 & 3.196 & 3.195 \\
\hline $\begin{array}{l}\text { Z65: Problemas relacionados com } \\
\text { outras circunstâncias } \\
\text { psicossociais }\end{array}$ & 220 & 211 & & 252 & 412 & 1.627 & 2.626 & 2.447 & 2.088 \\
\hline $\begin{array}{l}\text { F33: Transtorno depressivo } \\
\text { recorrente }\end{array}$ & & 291 & 1.001 & 1.193 & 1.049 & 1.022 & 1.060 & 1.150 & 1.104 \\
\hline F31: Transtorno afetivo bipolar & & & 422 & 576 & 551 & 522 & 481 & 536 & 478 \\
\hline $\begin{array}{l}\text { F10: Transtornos mentais } \\
\text { e comportamentais } \\
\text { devidos ao uso de álcool }\end{array}$ & & 220 & 383 & 344 & 313 & 263 & 249 & 232 & 218 \\
\hline F40: Transtornos fóbico-ansiosos & & & & 264 & 204 & 229 & & 252 & 213 \\
\hline
\end{tabular}

Fonte: Elaborada por Gabrielle Ota Longo; dados coletados junto ao Ministério da Previdência Social (BRASIL, 2006-2014) $)^{3}$.

Com base nos dados coletados, verificou-se que os oito transtornos mentais e comportamentais analisados posicionam-se na seguinte ordem decrescente de incidência entre os trabalhadores: o estresse, denominado 'Reações ao 'stress' grave e transtornos de adaptação (F43)", destaca-se em relação aos demais; os "Episódios depressivos (F32)", uma das formas pelas quais a depressão se manifesta; a ansiedade, denominada pela CID-10 como "Outros transtornos ansiosos (F41)"; os "Problemas relacionados com outras circunstâncias

\footnotetext{
${ }^{3}$ Utilizou-se como fonte de dados a Subseção C ("Acidentes do trabalho segundo a Classificação Internacional de Doenças - CID”) da Seção I ("Estatísticas de acidentes do trabalho") do Anuário estatístico de acidentes do trabalho, presente no endereço eletrônico do Ministério da Previdência Social.
} 
psicossociais (Z65)"4; o "Transtorno depressivo recorrente (F33)", sendo este outra manifestação da depressão; o "Transtorno afetivo bipolar (F31)"; os "Transtornos mentais e comportamentais devidos ao uso de álcool (F10)"; e os "Transtornos fóbico-ansiosos (F40)", que são os transtornos menos frequentes entre os oito analisados. Com exceção deste, que demonstrou um decréscimo no acometimento de trabalhadores, todos os outros sete acidentes de trabalho aumentaram entre o primeiro e o último ano analisados.

A Tabela 2, a seguir apresentada, demonstra a porcentagem dos oito acidentes do trabalho que acometem a saúde mental do trabalhador em relação ao total de acidentes de trabalho, trazendo, ainda, informações como o total de acidentes que impactam a saúde física e a quantidade dos que são qualificados como "outros" ou "ignorados" pela Previdência Social.

Tabela 2: Porcentagem dos oito acidentes de trabalho analisados em relação ao total de acidentes de trabalho, e os dados de "outros" e "ignorados", segundo o Ministério da Previdência Social.

\begin{tabular}{lrrrrrrrrr}
\hline & 2006 & 2007 & 2008 & 2009 & 2010 & 2011 & 2012 & 2013 & 2014 \\
\hline Mental & 4.204 & 10.465 & 16.053 & 16.431 & 15.013 & 16.820 & 18.677 & 20.869 & 20.008 \\
\hline Física & 487.798 & 623.175 & 709.035 & 687.452 & 664.979 & 673.576 & 664.984 & 672.890 & 654.374 \\
\hline Outros & 20.161 & 25.635 & 30.484 & 29.069 & 29.069 & 29.705 & 29.381 & 30.906 & 29.356 \\
\hline Ignorados & 69 & 248 & 408 & 413 & 413 & 528 & 942 & 999 & 398 \\
\hline Total & 512.232 & 659.523 & 755.980 & 733.365 & 709.474 & 720.629 & 713.984 & 725.664 & 704.136 \\
\hline Mental/Total & $0,82 \%$ & $1,59 \%$ & $2,12 \%$ & $2,24 \%$ & $2,12 \%$ & $2,33 \%$ & $2,62 \%$ & $2,88 \%$ & $2,84 \%$
\end{tabular}

Fonte: Elaborada por Gabrielle Ota Longo; dados coletados junto ao Ministério da Previdência Social (BRASIL, 2006-2014).

Destaca-se que, em todos os anos analisados, o montante que compõe a categoria "outros" supera o de acidentes que impactam a saúde psíquica. Isso pode indicar que os acidentes típicos, doenças do trabalho, acidentes de trajeto e/ou acidentes do trabalho sem CAT registrada, que não foram identificados como transtornos mentais ou comportamentais, seja em razão de uma perícia médica falha ou de outros fatores, podem ter sido registrados como "outros".

\footnotetext{
${ }^{4}$ Embora os "Problemas relacionados com outras circunstâncias psicossociais (Z65)" não estejam inseridos entre os transtornos mentais e comportamentais constantes do Capítulo V da CID-10, também são objeto de estudo justamente por decorrerem de circunstâncias psicossociais.

${ }_{5}^{5} \mathrm{O}$ termo "ignorados" refere-se a eventuais acidentes de trabalho, por situação de registro e motivo, segundo os 200 códigos da CID-10, mais incidentes no Brasil, no período de 2006 a 2014, não conhecidos pelo Ministério da Previdência Social. Nesse caso, o segurado da Previdência pode ter sofrido algum acidente laboral com impactos na sua saúde, mas não foi possível identificar tal acidente nem o caracterizar de acordo com um dos códigos da CID-10.
} 
O levantamento e análise dos dados expostos permitiram constatar que o Ministério da Previdência Social não faz referência ao assédio moral como causa dos referidos transtornos ou parte deles. $\mathrm{O}$ assédio moral sequer é mencionado entre os dados disponibilizados no endereço eletrônico consultado, ao contrário do que se verifica em relação à “Agressão por meio de força corporal (Y04)". Isso demonstra uma maior preocupação por parte da Previdência com as agressões físicas, em detrimento dos impactos psicológicos causados pelo assédio moral.

\subsection{Auxílios-doença acidentários segundo os códigos da Classificação Estatística Internacional de Doenças e Problemas Relacionados à Saúde - CID-10}

O auxílio-doença acidentário é o benefício concedido, mensalmente, ao segurado da Previdência Social incapacitado para o trabalho, desde que afastado por período superior a quinze dias em razão de acidente de trabalho ou de doença a este equiparada, relacionada ao desempenho de alguma atividade profissional.

Os “Transtornos mentais e comportamentais (F00-F99)" constantes do Capítulo V da Classificação Estatística Internacional de Doenças e Problemas Relacionados à Saúde (CID10) abrangem onze grupos assim denominados: "Transtornos mentais e orgânicos, inclusive os sintomáticos (F00-F09)"; "Transtornos mentais e comportamentais devido ao uso de drogas (F10-F19)"; "Esquizofrenia, transtornos esquizotípicos e transtornos delirantes (F20F29)"; "Transtornos do humor [afetivos] (F30-F39)"; "Transtornos neuróticos, transtornos relacionados com o stress e somatoformes (F40-F48)"; "Síndromes comportamentais associadas a disfunções fisiológicas e a fatores físicos (F50-F59)"; "Transtornos da personalidade e do comportamento do adulto (F60-F69)"; Retardo mental (F70-F79)"; "Transtornos do desenvolvimento psicológico (F80-F89)"; "Transtornos do comportamento e emocionais que aparecem na infância ou na adolescência (F90-F98)"; e "Transtorno mental não especificado (F99)".

Assim, a Tabela 3, a seguir apresentada, exibe os dados de auxílios-doença concedidos a segurados com tais transtornos: 
Tabela 3: Dados de auxílios-doença acidentários concedidos de janeiro de 2006 a junho de 2016 a segurados com "Transtornos mentais e comportamentais (F00-F99)" e seus grupos, presentes no Capítulo V da CID-10, segundo a Previdência Social.

\begin{tabular}{|c|c|c|c|c|c|c|c|c|c|c|c|}
\hline & 2006 & 2007 & 2008 & 2009 & 2010 & 2011 & 2012 & 2013 & 2014 & 2015 & $2016^{*}$ \\
\hline F00-F09 & 45 & 231 & 229 & 138 & 95 & 92 & 63 & 53 & 54 & 44 & 16 \\
\hline F10-F19 & 7 & 268 & 620 & 644 & 531 & 495 & 439 & 441 & 412 & 243 & 134 \\
\hline F20-F29 & 20 & 94 & 340 & 400 & 328 & 322 & 250 & 216 & 189 & 134 & 90 \\
\hline F30-F39 & 168 & 3.918 & 6.403 & 6.704 & 5.708 & 5.555 & 4.897 & 5.320 & 4.897 & 3.479 & 2.079 \\
\hline F40-F48 & 364 & 3.171 & 5.209 & 5.573 & 5.557 & 5.837 & 5.922 & 6.635 & 6.214 & 4.969 & 3.343 \\
\hline F50-F59 & 2 & 1 & 3 & 4 & 5 & 4 & 8 & 9 & 9 & 4 & 1 \\
\hline F60-F69 & 3 & 6 & 13 & 14 & 13 & 16 & 11 & 9 & 11 & 8 & 6 \\
\hline F70-F79 & 0 & 0 & 0 & 0 & 2 & 6 & 2 & 1 & 1 & 0 & 0 \\
\hline F80-F89 & 0 & 0 & 0 & 0 & 2 & 1 & 1 & 0 & 0 & 1 & 0 \\
\hline F90-F98 & 1 & 0 & 0 & 0 & 2 & 4 & 1 & 1 & 1 & 1 & 1 \\
\hline F99 & 2 & 1 & 1 & 1 & 0 & 1 & 3 & 3 & 3 & 1 & 3 \\
\hline Total & 612 & 7690 & 12.818 & 13.478 & 12.150 & 12.337 & 11.597 & 12.688 & 11.791 & 8.884 & 5.673 \\
\hline
\end{tabular}

Fonte: Elaborada por Gabrielle Ota Longo com dados coletados no endereço eletrônico do Ministério da Previdência Social (BRASIL, s.d.).

O total de auxílios-doença acidentários concedidos em face do diagnóstico de incapacidade para o trabalho resultante de "Transtornos mentais e comportamentais (F00F99)" apresentou um significativo aumento de 2006 a 2009, na proporção de pouco mais de vinte vezes; oscilou até 2013 e apresentou diminuição até 2016 (os dados disponíveis se referem ao período de janeiro a junho deste ano). Dentre o total de "Transtornos mentais e comportamentais (F00-F99)", destacam-se os "Transtornos do humor [afetivos] (F30-F39)" e os "Transtornos neuróticos, transtornos relacionados com o stress e somatoformes (F40F48)".

\subsection{A equiparação do assédio moral ao acidente de trabalho e suas repercussões jurídicas e sociais: uma análise crítica do Projeto de Lei no 7.202/2010}

Dentre as figuras equiparadas pela legislação previdenciária ao acidente de trabalho, destaca-se a inscrita no art. 21, inciso II, alínea b, da Lei ${ }^{\circ} 8.213 / 91$, referente às ofensas físicas intencionais, praticadas por colegas de trabalho ou por terceiros, em razão de disputa relacionada ao trabalho. Contudo, a equiparação não se estende às ofensas de natureza moral, como o assédio moral no meio ambiente do trabalho. 
Em 2010, com vistas a preencher essa lacuna, o legislador brasileiro apresentou o Projeto de Lei ${ }^{\circ} 7.202$ (BRASIL, 2010), que, mediante a alteração do referido texto da alínea b do inciso II do art. 21 da Lei ${ }^{\circ}$ 8.213/91, visa ampliar o conceito de acidente de trabalho, de modo a abranger as ofensas morais sofridas pelo segurado do Regime Geral de Previdência Social no local e no horário de trabalho, eliminando a exigência de o motivo da disputa estar relacionada ao trabalho.

Parte da doutrina também se posiciona pela equiparação do assédio moral ao acidente de trabalho (DUARTE; ALMEIDA, 2015), por consistir em uma circunstância relacionada às condições de trabalho e causadora de doenças ocupacionais (PRATA, 2008). Em outras palavras, trata-se de um fator de risco psicossocial capaz de provocar danos à saúde das vítimas (BARROS, 2011).

A equiparação é necessária, pois considerar o assédio moral como acidente de trabalho implica em garantir aos obreiros a mesma proteção conferida em situações nas quais o trabalhador é vítima de uma contingência assim caracterizada, conforme consta da justificativa do Projeto de Lei $n^{\circ} 7.202 / 2010$ (BRASIL, 2010). Assim, os trabalhadores vítimas de assédio moral passariam a ter direito a benefícios acidentários, Fundo de Garantia do Tempo de Serviço (FGTS) e estabilidade quando do retorno à atividade. Ademais, reforçaria a possibilidade de ajuizamento pelo trabalhador de ações cíveis reparatórias e de ações regressivas movidas pelo INSS, ambas em face do empregador.

Contudo, entende-se necessária a substituição da expressão "ofensa moral”, presente no texto proposto, por "assédio moral", de modo a não elastecer demasiadamente o conceito de acidente de trabalho. É importante, também, inserir na Lei $n^{\circ}$ 8.213/91 a definição de assédio considerada pela Previdência Social, abrangendo todos os elementos caracterizadores apontados neste estudo. Além disso, o nexo causal entre o assédio moral e as sequelas, como transtornos mentais e comportamentais, que reduzam ou impeçam o exercício das atividades laborais, deve ser perquirido por meio de perícia médica, realizada por equipe de profissionais multidisciplinar (com médico do trabalho especializado, psiquiatra, psicólogo, assistente social, enfermeiro), com capacitação técnica adequada.

Se mesmo assim a dificuldade de comprovar o nexo causal persistir, por se relacionar à própria natureza do transtorno, que tem sua origem pouco clara, deve-se primar pela aplicação do princípio da proteção, tão caro ao Direito do Trabalho. Na senda processual, por sua vez, impõe-se a justa distribuição dinâmica do ônus da prova, também acolhida pelo Novo Código de Processo Civil - Lei n ${ }^{\circ} 13.105 / 2015$, em seu artigo 373, parágrafo $1^{\circ}$. 


\section{ASSÉDIO MORAL NO CONTEXTO LABORAL: IMPACTOS LABOR- AMBIENTAIS, MEDIDAS PREVENTIVAS E REPRESSIVAS}

Os impactos labor-ambientais do assédio moral são diversos, abrangendo aspectos humanos (físicos e psicológicos), sociais e econômicos. Neste sentido, além do sofrimento, mal-estar, insatisfação e desmotivação do trabalhador, da incapacidade decorrente dos acidentes, aposentadorias precoces e do impacto negativo em inúmeras famílias, os encargos advindos desses males resultam em perdas econômicas imediatas para as empresas. São consequências comuns: baixa produtividade, perda de equipamentos, alto índice de absenteísmo e de rotatividade, maior número de faltas por motivos de saúde, pedidos de demissão, acidentes de trabalho e indenizações por dano moral (FLORINDO, 2013).

A Constituição Federal de 1988, em seu art. $7^{\circ}$, inciso XXII, assegura aos trabalhadores urbanos e rurais o direito à redução dos riscos inerentes ao trabalho, por meio de normas de saúde, higiene e segurança. Neste mesmo sentido, a Convenção $\mathrm{n}^{\circ} 155$ da Organização Internacional do Trabalho ressalta a necessidade de instituição de uma política nacional que priorize a prevenção de acidentes e de danos à saúde do trabalhador (ORGANIZAÇÃO INTERNACIONAL DO TRABALHO, 1983). Argumenta-se pela imprescindibilidade da eliminação do agente agressor, um dos quatro meios de prevenir os riscos e perigos do meio ambiente do trabalho (OLIVEIRA, 2002), sendo este o verdadeiro alcance da norma constitucional.

Pode-se enfrentar a prática do assédio moral no meio ambiente de trabalho através de medidas preventivas, que são mais eficientes e benéficas (NASCIMENTO, 2015), e de medidas repressivas, nas situações em que o assédio já se implementou e provocou danos. Para tanto, necessita-se de uma equipe multidisciplinar, constituída por diversos intervenientes, como profissionais de recursos humanos especializados em psicologia social ou do trabalho, psicólogos, assistentes sociais, médicos do trabalho, entidades sindicais, mediadores, bem como pesquisadores e operadores do Direito.

Deve-se designar a função de prevenção e intervenção em situações de assédio moral a um conselho constituído por membros eleitos pelos trabalhadores, para discutir e analisar tais conflitos em reuniões realizadas periodicamente, o que pode ser feito, provisoriamente, pela Comissão Interna de Prevenção de Acidentes (CIPA). Impõe-se a criação de um código de conduta, com programas específicos ao combate ao assédio moral, a informação dos trabalhadores e gerentes sobre a temática, o incentivo pelas empresas às boas relações de trabalho, o controle de absenteísmo injustificado, a avaliação dos riscos psicossociais 
existentes no meio ambiente laboral, a criação de instrumentos confiáveis e expeditos para a denúncia e apuração dos fatos, e o posicionamento contrário à prática em negociação coletiva de trabalho (NASCIMENTO, 2015).

Além das ações preventivas, por vezes, medidas repressivas ao assédio moral são necessárias. A partir da consciência por parte do trabalhador de que está sendo vítima de uma situação reiterada de violência psicológica, passa-se à identificação da agressão como assédio moral e do agressor (NASCIMENTO, 2015). Então, o apoio psicológico e o assessoramento jurídico são essenciais para ajudar a vítima a denunciar a situação, tanto para a própria empresa e ao respectivo sindicato, como à Delegacia Regional do Trabalho (DRT) ou ao Ministério Público do Trabalho (MPT), além de ajuizar a competente ação perante a Justiça do Trabalho.

Não apenas a empresa e a vítima, mas também outros atores têm importante papel a desempenhar nesse contexto. A mídia pode contribuir com a informação e conscientização dos leitores e telespectadores, para que possam melhor identificar situações de assédio moral e reagir rapidamente (HIRIGOYEN, 2015); o Ministério do Trabalho e Emprego, aprovando normas regulamentadoras relativas à segurança e medicina do trabalho e fiscalizando seu cumprimento, volta-se à efetiva proteção da saúde física e psíquica dos obreiros; os acadêmicos dedicados ao estudo e à pesquisa do Direito do Trabalho e da Saúde do Trabalhador, possibilitando o estudo e a elaboração de medidas para o enfrentamento do assédio moral, de modo a primar pela amenização da exploração do trabalho humano, que se realiza em nítido desvirtuamento da justiça (SOUTO MAIOR, 2000); e a Justiça do Trabalho, por sua vez, através da efetiva reparação de danos causados pelo assédio moral no ambiente de trabalho, visando à punição, ao desestímulo e à compensação do ofensor.

\section{CONCLUSÃO}

Proteger a integridade do trabalhador contra os perigos oriundos da realização da atividade laborativa significa respeitar o indivíduo como ser humano detentor de direitos. A dignidade humana não é garantida se o indivíduo é humilhado, estigmatizado, perseguido ou proscrito. Assim, medidas preventivas e repressivas mostram-se essenciais, diante dos inúmeros impactos labor-ambientais do assédio moral que envolvem aspectos humanos, econômicos e sociais. 
A efetiva proteção aos trabalhadores relaciona-se não somente a sua vida e integridade física, mas também à sua saúde psíquica. Conquanto o assédio moral nas relações laborais não seja um fenômeno recente, trata-se de um risco psicológico invisível, porém, concreto, nas relações de trabalho. Situa-se como um fator contemporâneo de precarização do trabalho, vez que desequilibra o meio ambiente do trabalho e afronta a dignidade e a integridade psicofísica do trabalhador, sendo reconhecido pela doutrina como causa de transtornos mentais ou comportamentais.

Dentre os acidentes do trabalho representados pelos 200 códigos da Classificação Estatística Internacional de Doenças e Problemas Relacionados à Saúde (CID-10) mais incidentes no Brasil, oito acometem a saúde mental dos trabalhadores; e a incapacidade para o trabalho provocada pelos "Transtornos mentais e comportamentais (F00-F99)" enseja a concessão de auxílios-doença acidentários. Todavia, a Previdência Social não faz referência ao assédio moral como causa dos referidos transtornos ou parte deles, ao contrário do que se verifica com a "Agressão por meio de força corporal (Y04)", indicando uma maior preocupação por parte da Previdência Social com agressões à integridade física dos trabalhadores, em detrimento da violência psicológica causada pelo assédio moral.

Diante de todo o exposto e para garantir às vítimas a mesma proteção conferida em caso de acidentes de trabalho, considera-se adequada a equiparação do assédio moral ao acidente de trabalho, sendo ou não por motivo de disputa relacionada ao trabalho, conforme proposto no Projeto de Lei $\mathrm{n}^{\mathrm{o}} 7.202 / 2010$. No entanto, ressalva-se a necessidade de que a expressão genérica "ofensa moral” seja substituída por "assédio moral", de modo a não ampliar demasiadamente o conceito de acidente de trabalho e a se referir, de modo específico e inequívoco, à perversa violência psicológica retratada neste estudo.

\section{REFERÊNCIAS}

ALMEIDA, Victor Hugo de; COSTA, Aline Moreira da; GOLÇALVES, Leandro Krebs. Meio ambiente do trabalho e proteção jurídica do trabalhador: (re)significando paradigmas sob a perspectiva constitucional. In: FELICIANO, Guilherme Guimarães; URIAS, João (Coords.). Direito ambiental do trabalho: apontamentos para uma teoria geral. São Paulo: LTr, 2013. v. 1.

; SOUZA, André Evangelista. O direito à saúde na perspectiva labor-ambiental. In: MIESSA, Élisson; CORREIA, Henrique. Temas atuais de Direito e Processo do Trabalho. Salvador: JusPODIVM, 2013. 
ALVARENGA, Rúbia Zanotelli de. Assédio moral organizacional. Revista de Direito do Trabalho, São Paulo, ano 38, n. 147, p. 11-31, jul./set. 2012.

BARROS, Alice Monteiro de. Curso de Direito do Trabalho. 7. ed. São Paulo: LTr, 2011.

BARUKI, Luciana Veloso. Riscos psicossociais e saúde mental do trabalhador: por um regime jurídico preventivo. São Paulo: LTr, 2015.

BENGOECHEA, Juan Antonio Sagardoy. Algumas notas sobre los derechos fundamentales em la empresa. Revista de Direito do Trabalho, São Paulo, ano 29, n. 111, jul./set. 2003.

BOBBIO, Norberto. A era dos direitos. Tradução de Carlos Nelson Coutinho. Rio de Janeiro: Campus, 1992.

BRANDÃO, Cláudio Mascarenhas. Proteção jurídica à saúde do trabalhador: uma necessária (re)leitura constitucional. Revista LTr, ano 74, n. 01, p. 24-29, jan. 2010.

BRASIL. Ministério da Previdência Social. Estatísticas. Dados abertos - Saúde e segurança do Trabalhador. Anuário estatístico de acidentes do trabalho - AEAT. Seção I - Estatísticas de acidentes do trabalho. Subseção C - Acidentes do trabalho segundo a Classificação Internacional de Doenças - CID. Brasília, DF, 2006 a 2014. Disponível em: $<\mathrm{http}$ ///www.previdencia.gov.br/dados-abertos/aeat-2013/estatisticas-de-acidentes-dotrabalho-2013/subsecao-c-acidentes-do-trabalho-segundo-a-cid/>. Acesso em: 28 ago. 2016.

Ministério da Previdência Social. Estatísticas. Dados abertos - Saúde e segurança do Trabalhador. Benefícios previdenciários e acidentários. Informações sobre auxílios-doença acidentários e previdenciários segundo os códigos da Classificação Internacional de Doenças - CID-10. Informações estatísticas relativas à segurança e saúde ocupacional. Tabelas - CID10. Auxílios-doença acidentários e previdenciários concedidos segundo os códigos da Classificação Internacional de Doenças - CID-10. Brasília, DF, s.d. Disponível em: <http://www.previdencia.gov.br/dados-abertos/estatsticas/tabelas-cid-10/>. Acesso em: 28 ago. 2016.

Ministério da Saúde. Organização Pan-Americana da Saúde no Brasil. Doenças relacionadas ao trabalho: manual de procedimentos para os serviços de saúde. Série A. Normas e Manuais Técnicos. n. 114. Brasília, DF, 2001. Organizado por Elizabeth Costa Dias. 
<http://bvsms.saude.gov.br/bvs/publicacoes/doencas_relacionadas_trabalho1.pdf $>$. Acesso em: 28 ago. 2016.

Projeto de Lei n. 7.202, de 28 de abril de 2010. Altera a alínea $b$ do inciso II do art. 21 da Lei $n^{\circ} 8.213$, de 24 de julho de 1991, para dispor sobre situação equiparada ao acidente de trabalho ao segurado do Regime Geral de Previdência Social. Diário da Câmara dos Deputados, Brasília, DF, 28 abr. 2010. Disponível em: <http://www.camara.gov.br/proposicoesWeb/fichadetramitacao?idProposicao=474888>. Acesso em: 28 ago. 2016.

DUARTE, Renan Fernandes; ALMEIDA, Victor Hugo de. O assédio moral como causador de doença ocupacional. Revista Laborativa, v. 4, n. 2, p. 4-25, out. 2015. Disponível em: <http://ojs.unesp.br/index.php/rlaborativa>. Acesso em: 28 ago. 2016.

FELICIANO, Guilherme Guimarães. Tópicos avançados de direito material do trabalho: atualidades forenses. São Paulo: Damásio de Jesus, 2006. v. 1.

FLORINDO, Valdir. Ambiente de trabalho + prevenção = - assédio moral. Revista LTr, v. 77, n. 10, p. 1180-1186, out. 2013.

HIRIGOYEN, Marie-France. Mal-estar no trabalho: redefinindo o assédio moral. Tradução de Rejane Janowitzer. 8. ed. Rio de Janeiro: Bertrand Brasil, 2015.

MELO, Sandro Nahmias. Meio ambiente do trabalho: direito fundamental. São Paulo: LTr, 2001.

NASCIMENTO, Amauri Mascaro. Curso de direito do trabalho: história e teoria geral do direito do trabalho: relações individuais e coletivas de trabalho. 28. ed. São Paulo: Saraiva, 2013.

NASCIMENTO, Sônia Mascaro. Assédio moral e dano moral no trabalho. 3. ed. São Paulo: LTr, 2015.

Assédio moral. 2. ed. São Paulo: Saraiva, 2011.

OLIVEIRA, Sebastião Geraldo de. Proteção jurídica à saúde do trabalhador. 4. ed. São Paulo: LTr, 2002. 
ORGANIZAÇÃO INTERNACIONAL DO TRABALHO. Convenção n. 155 da OIT. Aprovada na $67^{\mathrm{a}}$ reunião da Conferência Internacional do Trabalho. Genebra, 11 ago. 1983. Disponível em: <http://www.oitbrasil.org.br/node/504>. Acesso em: 28 ago. 2016.

PENIDO, Laís de Oliveira. Os fatores psicossociais e a caracterização do tratamento desumano e degradante. In: FELICIANO, Guilherme Guimarães [et al.] (Coords.). Direito ambiental do trabalho: apontamentos para uma teoria geral. São Paulo: LTr, 2015. v.2.

; PERONE, Giancarlo. Saúde mental no trabalho: esclarecimentos metodológicos para juristas. In: FELICIANO, Guilherme Guimarães [et al.] (Coords.). Direito ambiental do trabalho: apontamentos para uma teoria geral. São Paulo: LTr, 2015. v. 2.

PRATA, Marcelo Rodrigues. Anatomia do assédio moral no trabalho: uma abordagem transdisciplinar. São Paulo: LTr, 2008.

ROCHA, Júlio César de Sá da. Direito ambiental do trabalho. São Paulo: LTr, 2002.

SELIGMANN-SILVA, Edith; FIGUEIREDO, Marcelo; FRANCO, Tânia. As relações contemporâneas entre meio ambiente, trabalho e saúde mental. In: FELICIANO, Guilherme Guimarães [et al.] (Coords.). Direito ambiental do trabalho: apontamentos para uma teoria geral. São Paulo: LTr, 2015. v. 2.

SILVA, José Antônio Ribeiro de Oliveira. A saúde do trabalhador como um direito humano: conteúdo essencial da dignidade humana. São Paulo: LTr, 2008.

SOUTO MAIOR, Jorge Luiz. O direito do trabalho como instrumento de justiça social. São Paulo: LTr, 2000. 